\title{
A Preparative, Refractometric and Spectrophotometric Investigation of Some Phenoxysilanes
}

\author{
B E N G T S M I T H
}

\author{
Institutionen för Organisk Kemi, Chalmers Tekniska Högskola, Göteborg, Sweden
}

\begin{abstract}
The synthesis of phenoxyalkoxysilanes by various methods was studied. The refractometric properties and ultraviolet absorption spectra of the compounds prepared were measured. From the results obtained it was possible to draw certain conclusions concerning the charge distribution in the phenoxysilanes.
\end{abstract}

A

$\mathrm{s}$ an extension of previous studies of various types of silanes and siloxanes 1 an investigation of some phenoxysilanes, including phenoxymethoxysilanes, phenoxyethoxysilanes and tetraphenoxysilane from a preparative, refractometric, and spectrophotometric point of view is now reported.

\section{PREPARATION OF PHENOXYSILANES}

Several methods were tried. The first one involved the reaction between a phenoxychlorosilane and an alcohol, the second a controlled disproportionation of a phenoxyalkoxysilane, and in the third a tetraalkoxysilane was allowed to react with phenol in the presence of sodium phenoxide as a catalyst.

Method 1. Chlorosilanes usually react easily with alcohols with the exchange of alkoxy groups for chlorine. Thus the principal reaction product between a phenoxychlorosilane and an alcohol might be expected to be the corresponding phenoxyalkoxysilane. However, if the synthesis is made in the absence of an acceptor for hydrogen chloride this is by no means the case. Table 1 summarizes some preparations according to method 1. In run No.1, mainly phenoxytrimethoxysilane and tetraphenoxysilane were formed in a reaction between diphenoxydichlorosilane and methyl alcohol. Thus a considerable disproportionation took place.

The effect of a base is demonstrated in run No. 2. Here the synthesis in No. 1 was repeated using pyridine as an acceptor for the hydrogen chloride. Disproportionation was diminished appreciably and the yield of the required diphenoxydimethoxysilane increased from 5 to $47 \%$. To obtain a reasonable yield of triphenoxymethoxysilane from triphenoxychlorosilane and methyl

Acta Chem. Scand. 9 (1955) No. 8 

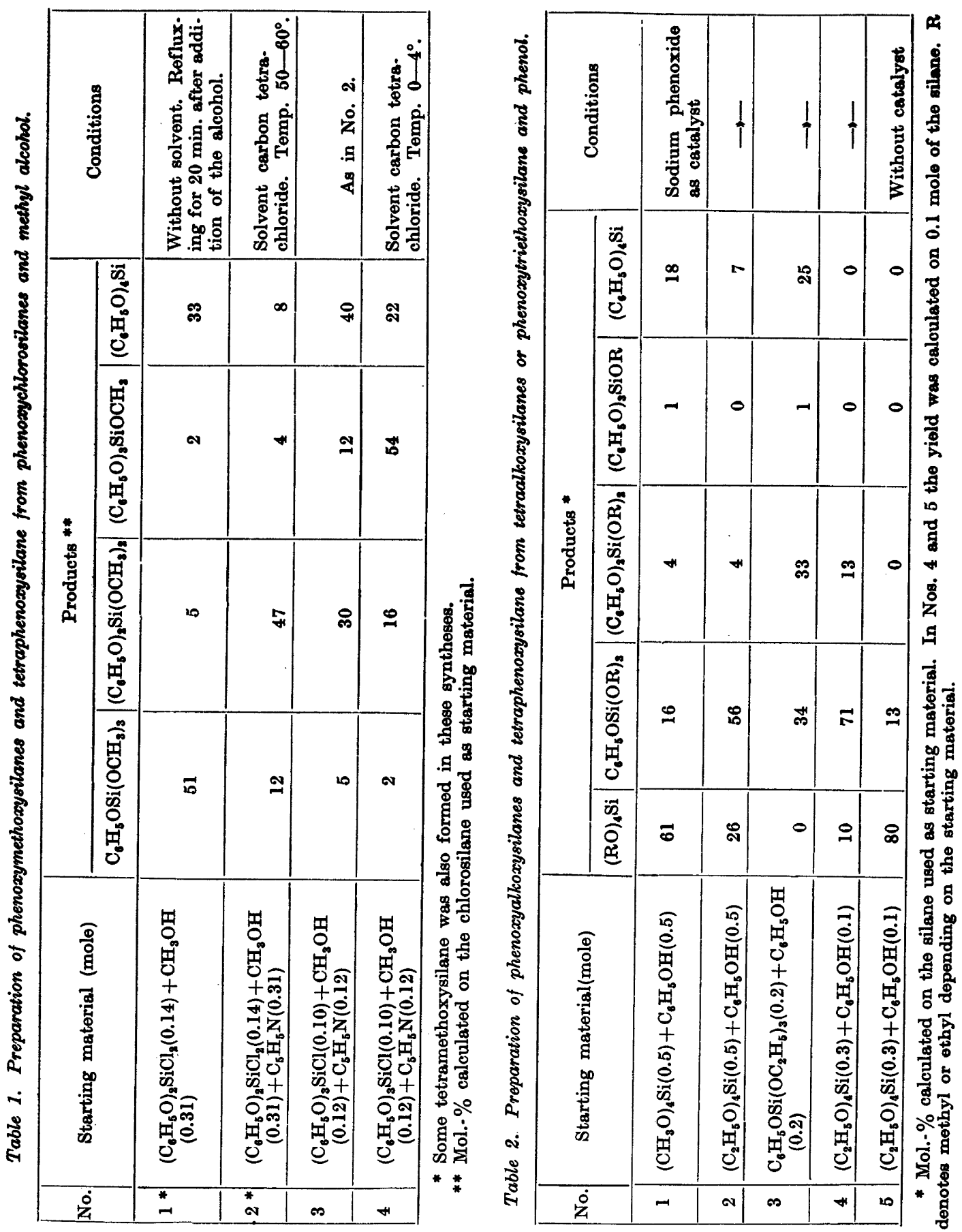

Acta Chem. Scand. 9 (1955) No. 8 
alcohol, however, it was not sufficient to absorb the hydrogen chloride but also necessary to carry out the reaction at a low temperature (cf. runs Nos. 3 and 4). A possible explanation of this fact will be given later in this paper.

Method 2. To examine the cause of the disproportionation of the phenoxyalkoxysilanes in the syntheses above some experiments were carried out. It was found that phenoxyalkoxysilanes could be heated, without appreciable change, in the presence of dry hydrogen chloride or small amounts of an alcohol or water. The simultaneous presence of hydrogen chloride and a hydroxylic compound, however, caused a disproportionation *. Furthermore it was found that the disproportionation could be controlled by using suitable conditions (see the experimental part). Thus it was possible from one phenoxyalkoxysilane to prepare the two "neighbours".

$$
\left(\mathrm{C}_{6} \mathrm{H}_{6} \mathrm{O}\right)_{n} \mathrm{Si}(\mathrm{OR})_{4-n} \rightleftharpoons\left(\mathrm{C}_{6} \mathrm{H}_{6} \mathrm{O}\right)_{n-1} \mathrm{Si}(\mathrm{OR})_{5-n}+\left(\mathrm{C}_{6} \mathrm{H}_{5} \mathrm{O}\right)_{n+1} \mathrm{Si}(\mathrm{OR})_{3-n}
$$

Method 3. The reaction between tetramethoxysilane and tetraethoxysilane, respectively, and phenol in equimolecular quantities and in the presence of sodium phenoxide is demonstrated by runs Nos. 1 and 2 of Table 2. The fact that a considerable part of the tetraalkoxysilanes remains after completion of the reaction and the formation of substantial amounts of tetraphenoxysilane indicates a ready reaction of the phenoxyalkoxysilanes with the phenoxide ion under the prevailing conditions. The same conclusion may be drawn from run No. 3, where phenoxytriethoxysilane and phenol were allowed to react in the molar ratio 1:1. Furthermore from the figures in runs Nos. 1, 2, and 3 it is evident that the reactivity of a silane $\left(\mathrm{C}_{6} \mathrm{H}_{5} \mathrm{O}\right)_{2} \mathrm{Si}(\mathrm{OR})_{4-\mathrm{a}}$ increases when $n$ increases from 1 to 3 and is greater for $\mathrm{R}=\mathrm{CH}_{3}$ than for $\mathrm{R}=\mathrm{C}_{2} \mathrm{H}_{5}$. The low yield of triphenoxyalkoxysilanes in all instances is noteworthy. Obviously these compounds, when formed, immediately react with phenoxide ion to tetraphenoxysilane.

To get a good yield of a particular phenoxyalkoxysilane from the alkoxysilane with one phenoxy group less, and phenol, it was necessary to use the alkoxysilane in excess (cf. run No. 4). A suitable inert diluent should also serve. In this way the formation of higher phenoxyalkoxysilanes was suppressed to a great extent. In the absence of a catalyst the exchange of phenoxy groups for alkoxy groups proceeded slowly and with a low yield of phenoxyalkoxysilanes ( $c f$. run No. 5) **.

The boiling points and analyses of the compounds prepared in this investigation are given in Table 3.

\footnotetext{
* Similar experiences were made by Peppard et. al. ${ }^{2}$ with mixed tetraalkoxysilanes.

** A new procedure for the alkoxylation of halosilanes using alkyl orthoformates was recently described by Shorr ${ }^{3}$. An attempt was made to prepare diphenoxydiethoxysilane by this mothod. However, an impure product was obtained (see the experimental part).
} 


\section{EXPERIMENTAL}

Phonoxymethoxysilanes from phenoxychlorosilanes and methyl alcohol (Method l).

Phenoxychlorosilanes. Jörg and Stetter prepared diphenoxydichlorosilane and triphenoxychlorosilane by adding silicon tetrachloride to molten phenol and then heating the mixture. They attempted, without success, to prepare phenoxytrichlorosilane by this mothod. Thompson and Kipping ' added a solution of phenol in benzene to boiling silicon tetrachloride whereupon the mixture was heated to $200^{\circ}$ for three to four hours. By this method all three of the phenoxychlorosilanes were obtained. The diphenoxy-and triphenoxychlorosilenes were obtained by Vol'nov ' in a reaction between phenyl acetate and silicon tetrachloride. A modification of the Thompson and Kipping procedure was used in the work described in this paper.

Phenol (23.5 g, 0.25 mole) was dissolved in $60 \mathrm{ml}$ of dry toluene and the solution added to $42.5 \mathrm{~g}(0.25 \mathrm{~mole})$ of silicon tetrachloride with rapid stirring. The mixture was heated to $100^{\circ}$ for one hour, the toluene and some unchanged silicon tetrachloride were removed and the residue fractionated in vacuum. There was obtained $25.0 \mathrm{~g}(44 \%)$ of phenoxytrichlorosilane, $10.5 \mathrm{~g}(15 \%)$ of diphenoxydichlorosilane and $6.3 \mathrm{~g}(7 \%)$ of triphenoxychlorosilane. The yield of the various phenoxychlorosilanes is dependent on the ratio of phenol to silicon tetrachloride, the amount of solvent used, and the heating time. By using suitable conditions it is possible to obtain any of the phenoxychlorosilanes as the principal product.

The boiling points of the phenoxychlorosilanes were: phenoxytrichlorosilane $70^{\circ}$ (9 $\mathrm{mm}$ ), diphenoxydichlorosilane $156-157^{\circ}(13 \mathrm{~mm})$, and triphenoxychlorosilane $210-$ $212^{\circ}(9 \mathrm{~mm})$. Their purity was ascertained by chlorine analyses.

Phenoxymethoxysilanes (Table 1). In run No. 1 the methyl alcohol was dropped into diphenoxydichlorosilane and the mixture heated to $60-70^{\circ}$ for 20 minutes. Fractionation yielded tetramethoxysilane, phenoxymethoxysilanes and a residue of tetraphenoxysilane which was recrystallized from petroleum ether.

When pyridine was used as hydrogen chloride acceptor (runs Nos. 2 and 3) the phenoxychlorosilane was dissolved in carbon tetrachloride and the mixture of methyl alcohol and pyridine then added by stirring. The temperature rose to $50-60^{\circ}$ during the addition. The precipitate of pyridine hydrochloride was filtered with the exclusion of moisture and washed with carbon tetrachloride; the solvent was distilled off at atmospheric pressure and the residue treated as above. In run No. 4 the heat of reaction was dissipated by cooling the reaction mixture with icewater during the addition of the methyl alcohol. pyrid ine mixture and the removal of the solvent was carried out at $30-35^{\circ}(180 \mathrm{~mm})$.

\section{Disproportionation of phenoxyalkoxysilanes}

$$
\text { (Meth od 2). }
$$

As an example of the application of this method the preparation of phenoxytrimeth. oxysilane and triphenoxymethoxysilane from diphenoxydimethoxsysilane is described.

To $27.6 \mathrm{~g}(0.1 \mathrm{~mole})$ of diphenoxydimethoxysilane was added one drop of methyl alcohol. A stream of dry hydrogen ehloride was bubbled through the mixture with simultaneous refluxing for one hour. Fractionation furnished $4.3 \mathrm{~g}(0.02 \mathrm{~mole})$ or $20 \%$ of phenoxytrimethoxysilane, $13.8 \mathrm{~g}(0.05 \mathrm{~mole})$ or $50 \%$ of diphenoxydimethoxysilane, and $7.1 \mathrm{~g}(0.021 \mathrm{~mole})$ or $21 \%$ of triphenoxymethoxysilane. A small residue of tetraphenoxysilane remained in the distillation flask. If the conversion of the diphenoxydimethexysilane is restricted to about $50 \%$ almost no tetramethoxysilane and tetraphenoxysilane are obtained.

\section{Phenoxysilanes from alkoxysilanes and phenol (Method 3)*.}

The alkox ysilane and phenol were mixed and a small amount of sodium added which dissolved as sodium phenoxide. Slow distillation, about 8 hours per mole of alcohol,

* This method was previously used by Malatesta 7 for the preparation of tetraphenoxysilane from tetraethoxysilane and phenol. 


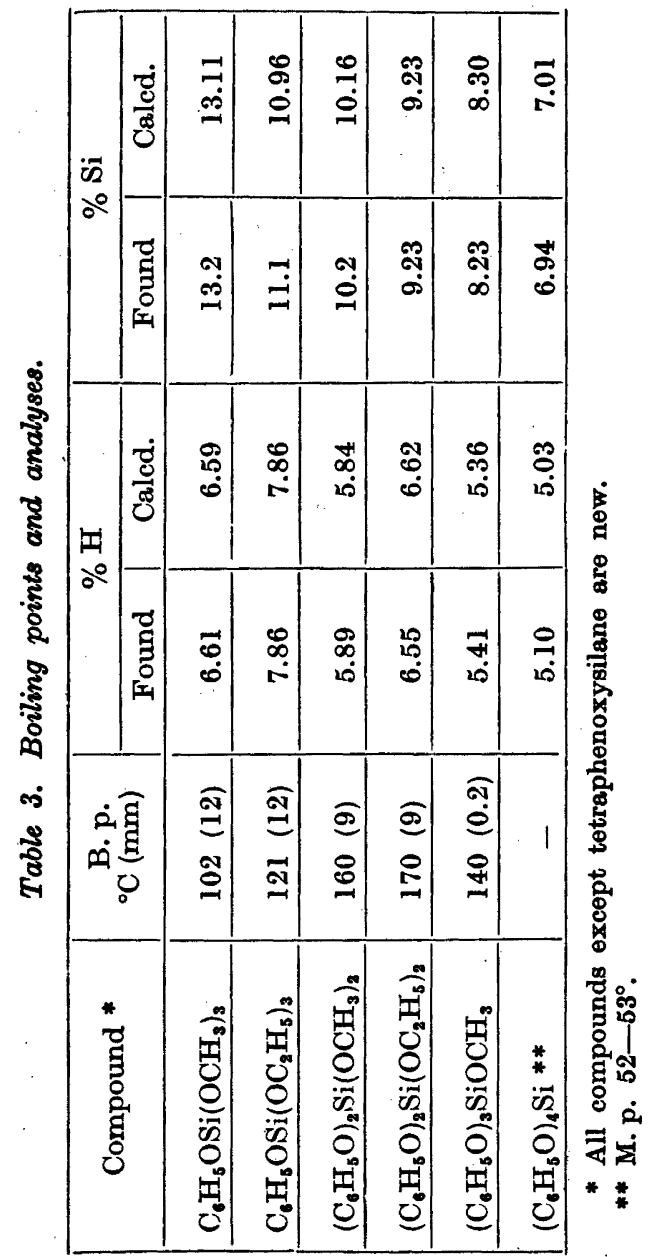

\begin{tabular}{|c|c|c|c|c|c|c|}
\hline$\frac{8}{4}$ & $\begin{array}{l}\text { P } \\
\text { id }\end{array}$ & $\underset{8}{\stackrel{9}{0}}$ & $\overrightarrow{0}$ & $\begin{array}{l}\text { \& } \\
\stackrel{1}{\infty} \\
\infty\end{array}$ & $\begin{array}{l}: 0 \\
\ddot{0}\end{array}$ & $\begin{array}{l}\underset{0}{0} \\
\underset{\infty}{\infty}\end{array}$ \\
\hline$\frac{2}{\Sigma}$ & 今ั & $\begin{array}{l}\text { ⿵్丶 } \\
\infty \\
0 \\
0\end{array}$ & $\begin{array}{l}\text { ন゙ } \\
\text { సే }\end{array}$ & $\begin{array}{l}\infty \\
\infty \\
\infty \\
\infty\end{array}$ & $\begin{array}{l}\tilde{m} \\
\overrightarrow{5}\end{array}$ & : \\
\hline 这 & $\stackrel{\oplus}{\not ்}$ & 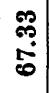 & 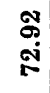 & 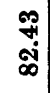 & $\begin{array}{l}\text { ది } \\
\text { జ் }\end{array}$ & $\begin{array}{l}\stackrel{乛}{0} \\
\stackrel{\oplus}{\exists}\end{array}$ \\
\hline 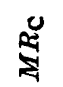 & $\begin{array}{l}\text { L } \\
\infty \\
\text { هి }\end{array}$ & 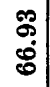 & $\begin{array}{l}\text { ํ. } \\
\text { ì }\end{array}$ & $\begin{array}{l}\infty \\
\infty \\
\infty \\
\infty\end{array}$ & $\vec{\infty}$ & $\underset{\mathcal{S}}{\stackrel{\mathcal{J}}{二}}$ \\
\hline$\beta_{R}^{\infty}$ & \begin{tabular}{l}
$\overline{8}$ \\
$\stackrel{8}{\circ}$ \\
\multirow{-}{*}{}
\end{tabular} & 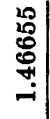 & 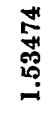 & 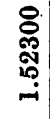 & $\underset{\sim}{\stackrel{乛}{*}}$ & 1 \\
\hline คి & $\begin{array}{l}\text { J゙! } \\
\stackrel{8}{\circ} \\
\stackrel{+}{*}\end{array}$ & 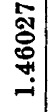 & 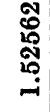 & 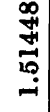 & 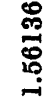 & 1 \\
\hline ซू & $\begin{array}{l}\stackrel{\Xi}{0} \\
\stackrel{0}{+}\end{array}$ & 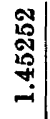 & 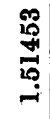 & 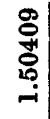 & 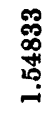 & 1 \\
\hline $2_{R}^{U}$ & 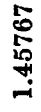 & 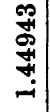 & $\underset{0}{\infty}$ & 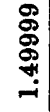 & 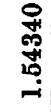 & 1 \\
\hline \&ु & ن. & 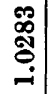 & 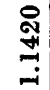 & 占 & 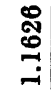 & 1 \\
\hline$\frac{\vec{B}}{\vec{B}}$ & 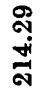 & 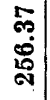 & 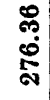 & $\begin{array}{l}\text { F̆ } \\
\text { +ें }\end{array}$ & 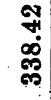 & 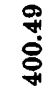 \\
\hline 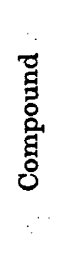 & 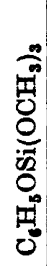 & $\begin{array}{l}0 \\
0 \\
0 \\
0 \\
0 \\
0 \\
0 \\
0 \\
0 \\
0 \\
0 \\
0 \\
0\end{array}$ & 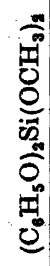 & 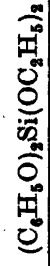 & 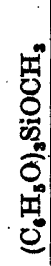 & $\begin{array}{l}0 \\
0 \\
0 \\
0 \\
0 \\
0 \\
0\end{array}$ \\
\hline
\end{tabular}

Acta Chem. Scand. 9 (1955) No. 8 
afforded an amount of alcohol equivalent to the amount of phenol used. The tetraalkoxy. silanes and phenoxyalkoxysilanes were fractionated and the residual tetraphenoxysilane recrystallized from petroleum ether (see also Table 2).

Diphenoxydiethoxysilanefrom diphenoxydichlorosilane and ethyl orthoformate.

A mixture of $14.3 \mathrm{~g}(0.05 \mathrm{~mole})$ of diphenoxydichlorosilane and $22.2 \mathrm{~g}(0.15 \mathrm{~mole})$ of ethyl orthoformate was heated to $70^{\circ}$ for one hour. Ethyl chloride was evolved. The ethyl formate formed and the excess of ethyl orthoformate were slowly distilled from the reaction mixture at atmospheric pressure and the residue fractionated in vacuum. There was obtained $2.2 \mathrm{~g}(17 \%)$ of phenoxytriethoxysilane, b. p. $102-104^{\circ}(5 \mathrm{~mm}), 9.5 \mathrm{~g}$ $(62 \%)$ of diphenoxydiethoxysilane, b. p. $152-154^{\circ}(5 \mathrm{~mm})$ and $3.0 \mathrm{~g} \mathrm{(17 \% )} \mathrm{of} \mathrm{presum-}$ ably triphenoxyethoxysilane, b. p. $196-197^{\circ}(5 \mathrm{~mm}), n_{\mathrm{D}}^{20}=1.535$. All of the products contained small amounts of chlorosilanes. Thus it appears that the alkoxylation of diphenoxydichlorosilane using this method is incomplete, at least under the conditions used here.

\section{REFRACTOMETRIC INVESTIGATION}

The phenoxyalkoxysilanes were redistilled to constant density and refractive index ( $n_{\mathrm{D}}^{20}$, Abbe-refractometer). For the samples thus obtained the refractive indices for the sodium $D$-line $(\lambda=5892.6 \AA)$, hydrogen $\mathrm{C}$ - and F-lines $(\lambda=6562.8 \AA$ and $4861.3 \AA$, respectively), and mercury $g$-line $(\lambda=4358.3$ A) were measured using a Bellingham and Stanley "Critical Angle Refractometer". These values together with densities and molar refractions (LorenzLorentz-formula) are listed in Table 4. This Table also gives the molar refractions of tetraphenoxysilane. Since tetraphenoxysilane is a solid the molar refractions were determined using an indirect method.

Solutions of tetraphenoxysilane in $n$-heptane were made up and the refractive indices and densities of the solutions measured. From these values the specific refractions of the solutions $\left(r_{s}\right)$ were calculated. The density and refractive indices of pure $n$-heptane were also measured and the specific refractions $\left(r_{h}\right)$ calculated. The specific refractions of pure tetraphenoxysilane $\left(r_{x}\right)$ were then obtained using the formula

$$
r_{x}=\frac{100 r_{s}-(100-p) r_{h}}{p}
$$

assuming the specific refractions of tetraphenoxysilane and $n$-heptane to be additive * ( $p$ is the weight- $\%$ of tetraphenoxysilane in the solution). Multiplication of the $r_{x}$-velues by the molar weight of tetraphenoxysilane gave the molar refractions.

For example, a solution of $0.5443 \mathrm{~g}$ of tetraphenoxysilane in $6.7968 \mathrm{~g}$ of $n$-heptane had $n_{\mathrm{C}}^{20}=1.39434, n_{\mathrm{D}}^{20}=1.39647, n_{\mathrm{F}}^{20}=1.40167, n_{\mathrm{g}}^{20}=1.40557$, and $d_{4}^{20}=0.7064$. From these data the following specific refractions were calculated by the L.L.-formula: $r_{\mathrm{C}}=0.33888, r_{\mathrm{D}}=0.34050, r_{\mathrm{F}}=0.34445$, and $r_{\mathrm{g}}=0.34740$. Pure $n$-heptane had $n_{\mathrm{C}}^{20}=1.38599, n_{\mathrm{D}}^{20}=1.38787, n_{\mathrm{F}}^{20}=1.39274, n_{\mathrm{g}}^{20}=1.39633, d_{\mathrm{S}}^{20}=0.68387, r_{\mathrm{C}}=0.34346$, $r_{D}=0.34495, r_{F}=0.34879$, and $r_{g}=0.35161$. Using eqn. 2 the following specific refractions were obtained for tetraphenoxysilane: $r_{C}=0.2816, r_{D}=0.2849, r_{F}=0.2903$, and $r_{B}=0.2948$.

- Several measurements at different concentrations indicated the validity of this assumption.

Acta Chem. Scand. 9 (1955) No. 8 
Table 5. Molar dispersions, specific refractions, specific dispersions and Abbe numbers.

\begin{tabular}{|c|c|c|c|c|c|}
\hline Compound & $M R_{\mathrm{F}}-M R_{\mathrm{C}}$ & $M R_{\mathrm{g}}-M R_{\mathrm{C}}$ & $r_{\mathrm{d}}$ & $r_{\mathrm{F}-\mathrm{C}}$ & $A$ \\
\hline $\mathrm{C}_{6} \mathrm{H}_{5} \mathrm{OSi}\left(\mathrm{OCH}_{3}\right)_{3}$ & 1.168 & 1.843 & 0.2482 & 106.5 & 39.2 \\
\hline $\mathrm{C}_{6} \mathrm{H}_{5} \mathrm{OSi}\left(\mathrm{OC}_{2} \mathrm{H}_{5}\right)_{3}$ & 1.392 & 2.192 & 0.2626 & 105.4 & 41.7 \\
\hline$\left(\mathrm{C}_{6} \mathrm{H}_{5} \mathrm{O}\right)_{2} \mathrm{Si}\left(\mathrm{OCH}_{3}\right)_{2}$ & 1.838 & 2.913 & 0.2639 & 135.2 & 33.4 \\
\hline$\left(\mathrm{C}_{6} \mathrm{H}_{5} \mathrm{O}\right)_{2} \mathrm{Si}_{\left(\mathrm{OC}_{2} \mathrm{H}_{5}\right)_{2}}$ & 1.997 & 3.163 & 0.2708 & 132.5 & 34.8 \\
\hline$\left(\mathrm{C}_{6} \mathrm{H}_{5} \mathrm{O}\right)_{3} \mathrm{SiOCH} \mathrm{H}_{3}$ & 2.504 & 3.851 & 0.2733 & 154.5 & 30.5 \\
\hline$\left(\mathrm{C}_{6} \mathrm{H}_{5} \mathrm{O}\right)_{4} \mathrm{Si}$ & 3.43 & 5.40 & - & - & - \\
\hline
\end{tabular}

In Table 5 the molar dispersions of the $\mathrm{F}-\mathrm{C}$ and $\mathrm{g}-\mathrm{C}$ lines are collected together with the specific refractions $\left[r_{\mathrm{D}}\right.$ (L.L.-formula)], specific dispersions $\left(r_{\mathrm{F}-\mathrm{C}}=\frac{n_{\mathrm{F}}-n_{\mathrm{C}}}{d^{20}} \cdot 10^{4}\right)$ and Abbe numbers $\left(A=\frac{n_{\mathrm{D}}-1}{n_{\mathrm{F}}-n_{\mathrm{C}}}\right)$. The bond refractions and bond dispersions of a phenoxy group bonded to silicon in various types of phenoxysilanes are listed in Table 6.

In a previous communication ${ }^{9}$ an identification scheme for organosilicon compounds, utilizing some refractometric constants, was proposed. Although it might be possible to identify phenoxyalkoxysilanes by chemical or spectrophotometric means it is considered of interest to include them in the refractometric identification system. As seen from the figures in Table 5 it is easy to distinguish between the mono-, di- and triphenoxyalkoxysilanes using the specific dispersions or Abbe numbers. The specific refractions are of less use

Table 6. Bond refractions and bond dispersions of the phenoxy group bonded to silicon.

\begin{tabular}{|c|c|c|c|c|c|c|}
\hline \multirow{2}{*}{ Compound } & \multicolumn{4}{|c|}{$r \lambda\left(\mathrm{Si}-\mathrm{OC}_{6} \mathrm{H}_{5}\right)$} & \multicolumn{2}{|c|}{$d \lambda_{,}-\lambda_{2}\left(\mathrm{Si}-\mathrm{OC}_{6} \mathrm{H}_{5}\right)$} \\
\hline & c & $\mathbf{D}$ & $\mathbf{F}$ & g & F-C & $g \cdot c$ \\
\hline $\mathrm{C}_{6} \mathrm{H}_{5} \mathrm{OSi}\left(\mathrm{OCH}_{3}\right)_{3}$ & 28.10 & 28.34 & 28.92 & 29.41 & 0.820 & 1.304 \\
\hline $\mathrm{C}_{6} \mathrm{H}_{5} \mathrm{OSi}\left(\mathrm{OC}_{2} \mathrm{H}_{5}\right)_{3}$ & 28.11 & 28.34 & 28.93 & 29.42 & 0.824 & 1.310 \\
\hline$\left(\mathrm{C}_{6} \mathrm{H}_{5} \mathrm{O}\right)_{2} \mathrm{Si}\left(\mathrm{OCH}_{3}\right)_{2}$ & 27.95 & 28.18 & 28.75 & 29.23 & 0.803 & 1.277 \\
\hline$\left(\mathrm{C}_{6} \mathrm{H}_{5} \mathrm{O}\right)_{2} \mathrm{Si}\left(\mathrm{OC}_{2} \mathrm{H}_{3}\right)_{2}$ & 27.99 & 28.22 & 28.80 & 29.28 & 0.809 & 1.287 \\
\hline$\left(\mathrm{C}_{8} \mathrm{H}_{5} \mathrm{O}\right)_{3} \mathrm{SiOCH}_{3}$ & 27.85 & 28.07 & 28.65 & 29.08 & 0.796 & 1.224 \\
\hline$\left(\mathrm{C}_{6} \mathrm{H}_{5} \mathrm{O}\right)_{4} \mathrm{Si}$ & 28.23 & 28.48 & 29.09 & 29.58 & 0.86 & 1.35 \\
\hline
\end{tabular}

Acta Chem. Scand. 9 (1955) No. 8 

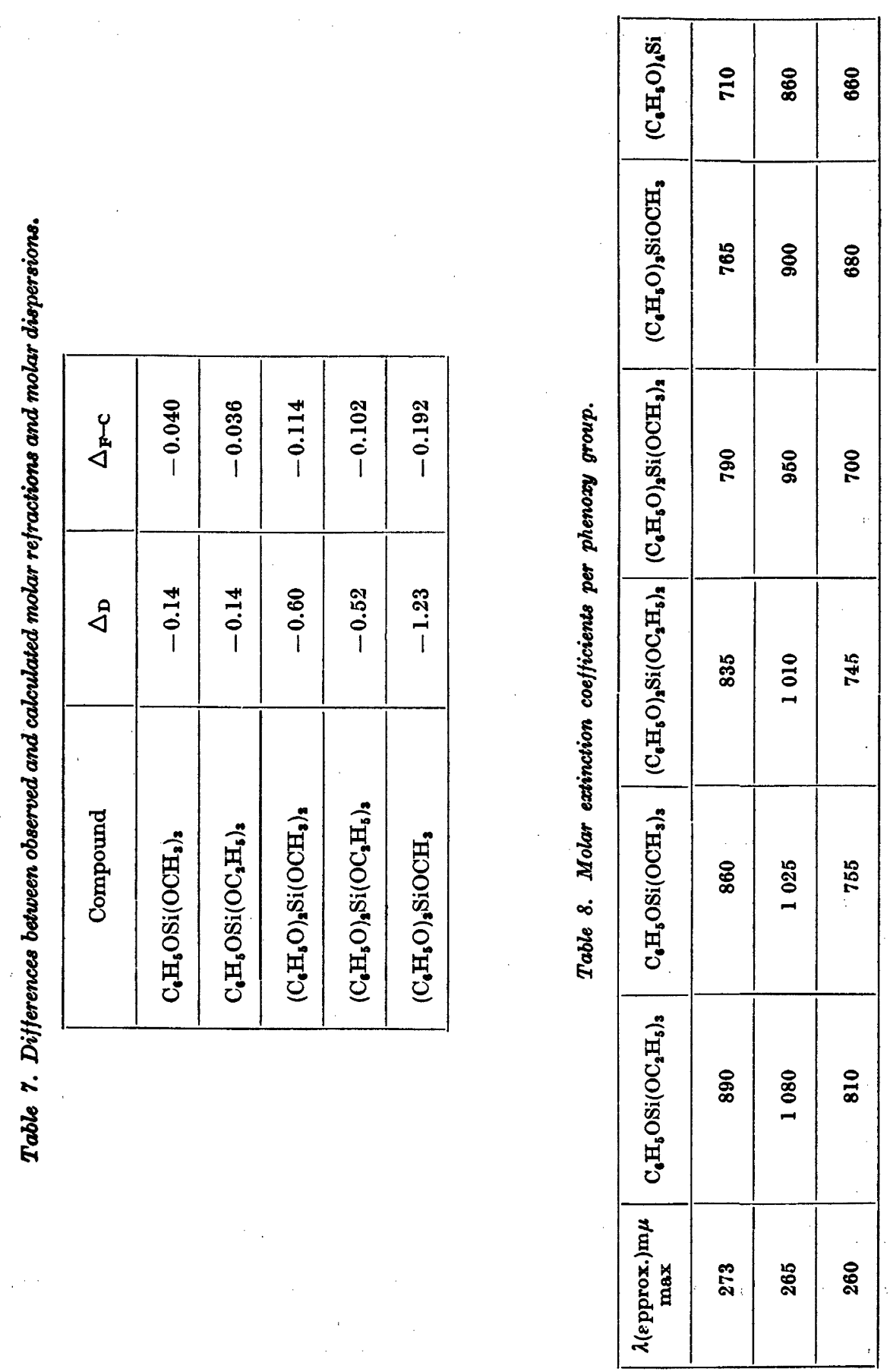

Acta Chem. Scand. 9 (1955) No. 8 
Figure 1. Absorption spectra of tetraphenoxysilane ( silane (-O-O-O-), diphenoxydiethoxysilane (- - -), diphenoxydimethoxysilane (........), phenoxytriethoxysilane (-.-.-), and phenoxytrimethoxysilane $(-+-+-)$.

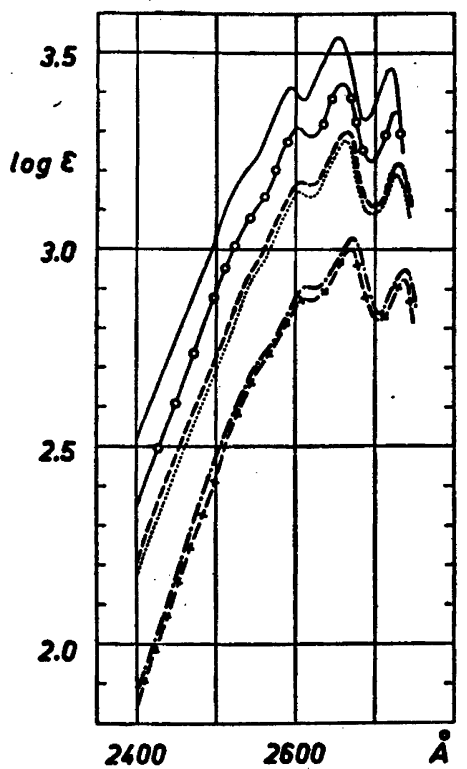

for this purpose. It is also possible to differentiate between the phenoxyalkoxysilanes and the eleven types of organosilicon compounds to which the refractometric identification method was previously applied (cf. Table 1, Ref ${ }^{9}$.).

The bond refractions and bond dispersions of a phenoxy group bonded to silicon which are listed in Table 6 were, in the case of tetraphenoxysilane, obtained by dividing the molar refractions and molar dispersions of this compound by four and in the case of the phenoxyalkoxysilanes by subtracting the normal bond values of the alkoxy groups from the molar refractions and molar dispersions *. From the figures in Table 6 it is evident that in the phenoxyalkoxysilanes either the bond values of the phenoxy group or alkoxy groups or, which is most likely, of both of them are different from the normal ones. On that account the discrepancies between the observed molar refractions and molar dispersions and those calculated from the normal bond values are considerable (cf. Table 7).

When calculating molar refractions and molar dispersions of phenoxyalkoxysilanes the bond values of the phenoxy groups in Table 6 should be used together with the normal bond values of the alkoxy groups taken from Ref. ${ }^{1}$ (cf. Tables 37, 38, 39, 48, 49, and 50 of this reference). Although Table 6 only

* The bond refraction of a group $\mathrm{X}$ bonded to silicon is written $r(\mathrm{Si}-\mathrm{X})$ and means the sum of the refraction of the group $\mathrm{X}$ and the bond $\mathrm{Si}-\mathrm{X}$. The normal value of the bond refraction $r(\mathrm{Si} \cdot \mathrm{X})$ is defined as the bond refraction of the group in the silane $\mathrm{SiX}_{\mathrm{n}}$, where $\mathrm{n}$ equals 4 in the present case. The normal bond refraction is obtained by dividing the molar refraction of the silane $\mathrm{SiX}_{4}$ by 4. Thus the normal bond refractions of the phenoxy group bonded to silicon are tabulated in the last row of Table 6. Concerning the bond dispersions $d(\mathrm{Si}-\mathrm{X})$ the same applies as to the bond refractions. The normal bond values of the alkoxy groups used in the calculation were taken from Ref. ${ }^{1}$.

Acta Chem. Scand. 9 (1955) No. 8 
lists bond values of phenoxy groups in phenoxymethoxy- and phenoxyethoxysilanes it is believed that these values may also be used in calculating molar refractions and molar dispersions of phenoxyalkoxysilanes with other types of alkoxy groups.

\section{SPECTROPHOTOMETRIC INVESTIGATION}

The ultraviolet absorption of the phenoxysilanes was measured in $n$ heptane solution in the range $240-275 \mathrm{~m} \mu$ using a Hilger UVISPEK spectrophotometer (see Fig. 1). The molar extinction coefficients per phenoxy group are given in Table 8. It is seen that in the series tetraphenoxysilane-triphenoxyalkoxysilane-diphenoxydialkoxysilane-phenoxytrialkoxysilane there is a bathochromic shift. Likewise a bathochromic shift exists between the corresponding phenoxymethoxysilanes and phenoxyethoxysilanes. The shifts are accompanied by hyperchromic effects as shown by the figures of the molar extinction coefficients per phenoxy group. The significance of the spectra will be further discussed below.

\section{DISCUSSION}

The reaction between a chlorosilane and an alcohol may be assumed to proceed in the same way as the reaction between an acid chloride and an alcohol * (cf. Ref. ${ }^{11}$, p. 195).

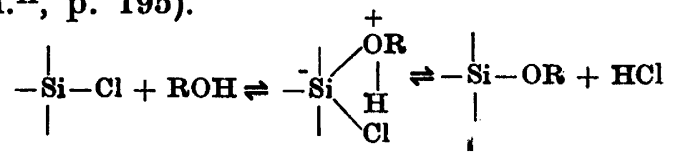

A proof of the formation of intermediate addition compounds between chlorosilanes and alcohols has been given by Troost ${ }^{12}$ who isolated adducts between silicon tetrachloride and alcohols at a low temperature. Similar addition compounds between silicon tetrafluoride and alcohols were reported by Gierut et al. ${ }^{13}$. In the absence of reactive groups other than chlorine at the silicon atom the only disturbance of the above reaction that may occur is hydrolysis of the chlorosilane or alkoxysilane by water formed in a side reaction between hydrogen chloride and the alcohol (cf. Ref. ${ }^{1}$ ). However, if other reactive groups are present (in the case of the phenoxychlorosilanes phenoxy groups) complications may arise as exemplified by synthesis No. 1 of Table 1. As pointed out previously the disproportionation is orginated by the simultaneous presence of hydrogen chloride and an alcohol. This fact indicates that the cause of the disproportionation is an acid-catalyzed re-esterification of the phenoxychlorosilane and/or phenoxyalkoxysilane.

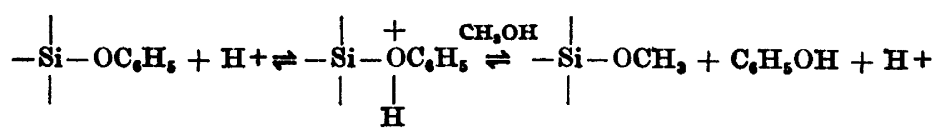

If the phenol then reacts with another silane molecule than that from which it was formed, for instance by the exchange of a phenoxy group for a methoxy

- A similar mechanism was proposed by Swain et al.10 for the hydrolysis of halogenosilanes which reaction was shown to proceed by a $S_{\mathrm{N}^{2}}$ attack by a water molecule on the halogenosilane. 
group or a chlorine atom, this molecule gains one phenoxy group and the transference of a phenoxy group from one silane molecule to another is explained.

In the reactions between phenoxychlorosilanes and methyl alcohol using pyridine as a hydrogen chloride acceptor it was observed that the extent to which pyridine hindered the disproportionation in the case of the triphenoxychlorosilane was dependent on the temperature. A low temperature was necessary to obtain a reasonable yield of triphenoxymethoxysilane. No such temperature dependence was observed in the case of diphenoxydichlorosilane (cf. syntheses Nos. 2, 3, and 4, Table 1).

The function of pyridine or other tertiary amines in the reaction between halogenosilanes and alcohols has generally been considered to be merely that of a hydrogen chloride acceptor in spite of the fact that addition compounds between halogenosilanes and tertiary amines have been known to exist for a long time. ${ }^{14},{ }^{15}$. It is very likely, however, that the tertiary amine takes a more active part in the reaction and that the real "acylating" reagent is an addition compound between the amine and the chlorosilane*.

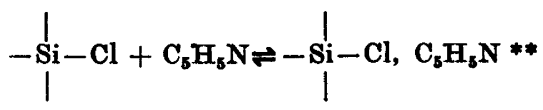

Such an assumption is supported by the observations made in this work and elsewhere***. The stability of the addition compound should, among other things, be dependent on the structure of the chlorosilanes. From steric considerations the addition compound between pyridine and triphenoxychlorosilane might be expected to be less stable than that between pyridine and diphenoxydichlorosilane (cf. F-strain in amine salts ${ }^{21}$ ). If it be assumed that the extent to which pyridine hinders the disproportionation reaction is a function of the stability of its addition compound with the chlorosilane the influence of the temperature on the reaction between the phenoxychlorosilanes and methyl alcohol in the presence of pyridine is understandable.

The nucleophilic displacement of an alkoxy group by a phenoxy group was utilized in the third method used in this work for the preparation of phenoxyalkoxy silanes.

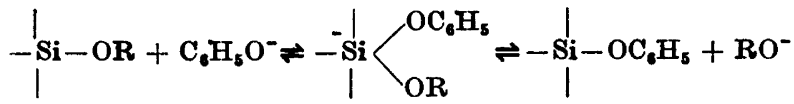

$$
\begin{aligned}
& \mathrm{RO}^{-}+\mathrm{C}_{6} \mathrm{H}_{5} \mathrm{OH} \rightleftharpoons \mathrm{ROH}+\mathrm{C}_{6} \mathrm{H}_{5} \mathrm{O}^{-}
\end{aligned}
$$

* It has been proposed that the promoting action of pyridine in benzoylation reactions is due to the formation of quaternary addition compounds between pyridine and benzoyl chloride (Ref. ${ }^{11}$, p. 198). Furthermore acetylpyridinum chloride is a well known analytical reagent for the determination of active hydrogen in the hydroxyl groups of alcohols and phenols ${ }^{16}$.

** The nature of the addition compounds is not definitely established. They have been formulated as co-ordination compounds in which use is made of vacant silicon orbitals, but also a quaternary salts ${ }^{17-20}$.

*** In the preparation of dimethyldialkoxysilanes and diphenyldialkoxysilanes from the corresponding chlorosilanes and alcohols, the reaction was incomplete in the absence of a tertiary amine. In the presence of pyridine, however, all of the chlorine atoms were replaced by alkoxy groups. The effect of pyridine can hardly be attributed to its salt formation with hydrogen chloride only, as other means of removing the hydrogen chloride e. $g$. boiling or blowing an inert gas through the reaction mixture were without effect 1 .

Acta Chem. Scand. 9 (1955) No. 8 
From the figures of Table 2 it is apparent that the reactivity of phenoxyalkoxysilanes for phenoxide ion increases in the series

$$
\mathrm{C}_{6} \mathrm{H}_{6} \mathrm{OSi}(\mathrm{OR})_{3}<\left(\mathrm{C}_{6} \mathrm{H}_{5} \mathrm{O}\right)_{2} \mathrm{Si}(\mathrm{OR})_{2}<\left(\mathrm{C}_{6} \mathrm{H}_{5} \mathrm{O}\right)_{2} \mathrm{SiOR}
$$

and is greater for $\mathrm{R}=\mathrm{CH}_{3}$ than for $\mathrm{R}=\mathrm{C}_{2} \mathrm{H}_{5}$. This means that the positive charge on the silicon atom also increases in the mentioned series and is greater in the phenoxymethoxysilanes than in the corresponding phenoxyethoxysilanes. Such a charge distribution might be anticipated in view of the greater electron attraction of the phenoxy group in comparison with the alkoxy groups and the difference in inductive effects of the methyl and ethyl groups.

It is of interest that the difference in charge on silicon is also manifested in the absorption spectra of the phenoxysilanes. The ultraviolet absorption of these compounds originates from the aromatic part of the molecule. Mulliken ${ }^{22}$ and others have stated from wave-mechanical considerations that absorption of light takes place predominantly through transitions to chargeresonance structures. Accordingly the transition energy is dependent on the resonance in the molecule. In the present case resonance occurs between such forms as *<smiles></smiles>

The difference in energy between the ground state and the excited states is diminished with increased contribution of polar structures as a result of the lowering of the potential energy of the excited states. At the same time there is an increase in the molar extinction coefficients and bathochromic shifts take place ${ }^{24}$.

The resonance in the phenoxysilane is dependent on the charge on the silicon atom in such a way that the contribution of polar structures decreases with increased positive charge **. Consequently from the study of the absorption curves in Fig. 1 and the molar extinction coefficients per phenoxy group in Table 8 it is apparent that the silicon atom in tetraphenoxysilane has the greatest positive charge which then decreases as alkoxy groups are exchanged for phenoxy groups. The greater positive charge on the silicon atom of the phenoxymethoxysilanes as compared with the corresponding phenoxyethoxysilanes is also clearly shown.

The differences between the molar refractions, calculated for the phenoxyalkoxysilanes from the normal bond refractions of the phenoxy and alkoxy groups and the molar refractions found, are appreciable*** (cf. Table 7). In

* To explain the acidity of the silanols $\mathrm{R}_{\mathrm{g}} \mathrm{SiOH}$ the participation of resonance structures such as $\mathrm{R}_{3} \mathrm{Si}=\mathrm{O} \stackrel{+}{\mathrm{H}}$ have been proposed ${ }^{23}$. In view of this resonance structures such as $\overline{\mathrm{Si}}=\stackrel{+}{\mathrm{O}}-\mathrm{C}_{6} \mathrm{H}_{5}$ and $\overline{\mathrm{Si}}=\stackrel{+}{\mathrm{O}}-\mathrm{R}$ might contribute to the state of the phenoxyalkoxysilanes. At present there is no evidence, however, of the existence of such forms. While it seems unlikely that the contribution of the first type should be significant, the existence of the second might explain the variation of the apparent bond refraction of the phenoxy group bonded to silicon (see Table 6).

** Disturbances may arise, however, if steric hindrance is present ${ }^{25}$.

*** Similar deviations were previously shown to exist for the alkylalkoxysilanes 1 $\left[R S i(O R)_{3}(-0.10 \mathrm{ml}), R_{2} \operatorname{Si}(O R)_{2}(-0.20 \mathrm{ml})\right.$ and $\left.R_{3} \operatorname{SiOR}(-0.10 \mathrm{ml})\right]$. 
all probability this result has to be ascribed to the variation in charge on silicon. The differences increase as alkoxy groups are successively replaced by phenoxy groups indicating that a tightening of the $\mathrm{Si}-\mathrm{O}$ bond of the alkoxy group is the main cause of the deviations (cf. note p. 1348).

\section{REFERENCES}

1. Smith, B. Kiselorganiska Studier (Diss.) Gothenburg, 1951.

2. Peppard, D. F., Brown, W. G. and Johnson, W. C. J. Am. Chem. Soc. 68 (1946) 70.

3. Shorr, L. M. J. Am. Chem. Soc. 76 (1954) 1390.

4. Jörg, H. and Stetter, J. J. prakt. Chem. [2] 117 (1927) 305.

5. Thompson, R. A. and Kipping, F. S. J. Chem. Soc. 19291176.

6. Vol'nò, Y. N. J. Gen. Chem. (U.S.S.R.) 9 (1939) 2269.

7. Malatesta, L. Gazz. chim. ital. 78 (1948) 747.

8. Bauer, N. and Fajans, K. in Weissberger, A. (Ed.) Physical Methods of Organic Chemistry, Part II, 2nd Ed., Interscience Publishers, New York 1949, p. 1160.

9. Smith, B. Svensk Kem. Tidskr. 64 (1952) 330.

10. Swain, C. G., Esteve, R. M. and Jones, R. H. J. Am. Chem. Soc. 71 (1949) 965.

11. Day, A. R. Electronic Mechanisms of Organic Reactions, American Book Company, 1950.

12. Trost, W. R. Nature 169 (1952) 289 .

13. Gierut, J. A., Sowa, F. J. and Niewland, J. A. J. Am. Chem. Soc. 58 (1936) 786.

14. Harden, A. J. Chem. Soc. 51 (1887) 40.

15. Reynolds, J. E. J. Chem. Soc. 95 (1909) 512.

16. Smith, D. M. and Bryant, W. M. D. J. Am. Chem. Soc. 57 (1935) 61.

17. Trost, W. R. Can. J. Chem. 29 (1951) 877; 30 (1952) 835, 842.

18. Emeléus, H. J. and Miller, N. J. Chem. Soc. 1939819.

19. Burg, A. B. J. Am. Chem. Soc. 76 (1954) 2674.

20. Piper, T. S. och Rochow, E. G. J. Am. Chem. Soc. 76 (1954) 4318.

21. Ferguson, L. N. Electron Structures of Organic Molecules, Prentice-Hall Inc., Now York 1952, p. 111 ff.

22. Mulliken, R. S. J. Chem. Phys. 7 (1939) 20.

23. Gilman, H. and Dunn, G. E. Chem. Revs. 52 (1953) 104.

24. Ferguson, L. N. Chem. Revs. 43 (1948) 385.

25. Work to be published in Acta Chem. Scand.

Received June 18, 1955. 